\title{
A ALIENAÇÃO COMO PROCESSO DE DES- NATURAÇÃO DO INDIVÍDUO E SUA NOVA EXISTÊNCIA SOCIAL EM JEAN-JACQUES ROUSSEAU
}

\author{
Juliana Fischer de Almeida ${ }^{1}$ \\ Pontifícia Universidade Católica do Paraná (PUC/PR) \\ (D) https://orcid.org/0000-0002-6581-9389
}

\begin{abstract}
RESUMO:
$\mathrm{O}$ presente artigo pretende investigar de que forma a alienação social acarreta o processo de desnaturação do indivíduo e propugna pela formulação de uma nova existência. $\mathrm{O}$ "eu" social é corrompido pelo meio no qual vive sendo impossível viver solitariamente. A "luz" da razão acarreta a decadência moral, proporcionando um desequilíbrio entre razão e sentimento. A dicotomia entre aparência e autenticidade realizada por Rousseau será analisada sob o ponto de vista antropológico e suas consequências políticas.
\end{abstract}

PALAVRAS-CHAVE: Alienação social; Existência; Aparência; Autenticidade.

\section{ALIENATION AS AN INDIVIDUAL DENATUR- ATION PROCESS AND ITS NEW SOCIAL EX- ISTENCE IN JEAN-JACQUES ROUSSEAU}

\begin{abstract}
:
The present article intends to investigate in what way the social alienation entails the process of denaturation of the individual and advocates for the formulation of a new existence. The social "I" is corrupted by the environment in which it lives impossible to live alone. The "light" of reason leads to moral decay, providing an imbalance between reason and feeling. Rousseau's dichotomy between appearance and authenticity will be analyzed from the anthropological point of view and its political consequences.
\end{abstract}

KEYWORDS: Social alienation; Existence; Appearance; Authenticity.

\footnotetext{
${ }^{1}$ Doutoranda em Filosofia pela Pontifícia Universidade Católica do Paraná (PUC/PR), Paraná - Brasil. Bolsista PUC/PR. E-mail: juliana_fisalm@yahoo.com.br

A alienação como processo de desnaturação do indivíduo e sua nova existência social em Jean-Jacques Rousseau Juliana Fischer de Almeida
} 
O ponto de partida a ser analisado é a obra Discurso sobre as ciências $e$ as artes, também conhecido como Primeiro discurso, cuja alienação de si decorre de como os laços sociais já instituídos impossibilitam a transparência nas relações sociais e com sua própria consciência. Uma primeira problemática poderia ser formulada como: de que maneira a alienação contribui para a dissolução do "eu" e pela imposição de obstáculos à solidão?

Para responder à questão, faz necessário compreender que a noção da solidão no Primeiro Discurso se relaciona com a moral, porquanto os valores estão em degradação, à aparência é mais importante do que realmente ser. A falta de virtude gera um problema, sobretudo político, uma vez que a noção de bem público se altera, passando a ser mais uma forma de contemplar os interesses privados.

Para entender o problema da alienação em Rousseau, Charles Taylor (1997, p. 458), na obra As Fontes do Self, registra que a cultura nos afasta da natureza, no seguinte sentido:

\begin{abstract}
A natureza é fundamentalmente boa, e a alienação que nos deprava é o que nos separa dela. [...] O impulso original da natureza é correto, mas o efeito de uma cultura depravada é que perdemos contato com ele. Sofremos essa perda porque não dependemos mais de nós mesmos e desse impulso e sim das outras pessoas e do que pensam a nosso respeito, do que esperam de nós, do que admiram ou desprezam em nós, recompensam ou punem em nós. Estamos separados da natureza pela densa teia de opiniões crida entre nós na sociedade e não conseguimos mais recuperar o contato com ela.
\end{abstract}

Taylor defende que a ideia de Rousseau era recuperar o contato com a natureza sem a dependência calculista do outro, da força de opinião e das ambições geradas pela força desenfreada da razão em detrimento da natureza - voz interior, sentimento. A cultura, a ciência e as artes, de certo modo, mascaram os verdadeiros elos sociais que impedem a consciência de se expressar no ser e no coração dos membros da sociedade. O enaltecimento da "luz" da razão ocasiona a decadência moral, pois o impulso natural é abafado pelo uso da racionalidade desproporcional ao sentimento e pela transparência de um "eu" perdido entre as esferas sociais depravadas, ocorrendo uma dissolução do "eu".

Assim, como o intento de equilibrar razão e sentimento não é possível, o laço entre os membros da comunidade é reduzido aos interesses particulares e à dependência mútua, criando necessidades artificias nos homens. A vida social é um jogo de interesses individuais que se contrapõem ao significado do próprio sentido de se viver em sociedade, destruindo-se mutuamente, ao invés de unirem-se para promoção do bem comum. O homem torna-se uma presença aparente que corrói o ser; a ordem 
social é a verdadeira desordem, restando, assim, caracterizada a oposição rousseauniana entre ser e parecer, como o princípio norteador de sua análise social. Na vida em sociedade, os interesses se conflitam, gerando a desigualdade e a opressão de uma parte sobre o todo. De acordo com Baczko (1974, p. 17):

\begin{abstract}
a oposição entre interesses particulares tem o efeito de que "ninguém quer o bem público quando ele concorda com si próprio", embora "todos fingem em querer sacrificar seus interesses em prol do bem público". As leis do Estado, que deveriam ter a expressão dos interesses ou da vontade da sociedade como um todo, tornam-se instrumento de dominação dos poderosos pelos fracos, em virtude do "direito do mais forte". Mas "a força é um poder psíquico", e não um vínculo moral que pode resultar apenas na aparência de uma lei existente para a sociedade; o Estado e as leis são "exteriores" em relação aos indivíduos, uma vez que dividem e não unem ao todo. Na sociedade os interesses se cruzam, engendram um mundo de simples aparência; cada um se comporta de forma egoísta, e a razão de cada ação é interessada, basta saber os "interesses (pessoais) para adivinhar sobre o que elas dizem de cada coisa". Mas esta simples aparência dissimula algo extremamente complexo. Na descrição da sociedade por Rousseau, uma das principais razões é a complexidade das relações sociais depois da mútua dependência entre os homens, devido à existência das necessidades artificias e do reino das "opiniões". "Todo universo (torna-se) necessário para cada homem", "o homem em sociedade procura estender-se".
\end{abstract}

Na passagem, fica claro que a noção de bem público é camuflada por interesses privados, sendo que a ação dentro da sociedade não condiz com a real natureza do ser humano. O agir desconectado da fala produz instrumentos de opressão, chegando a legitimar o direito do mais forte algo que será melhor estudado no transcorrer do trabalho - gerando uma dependência entre os homens, não justificada pelo sentimento de si e de pertencimento à comunidade livre e igual. A oposição entre interesses particulares marca o processo de desintegração social e da consciência de si, tornando a aparência um complexo modelo para explicar a sociedade. O homem social começa a se reconhecer nas coisas, algo exterior o caracteriza, desnaturando-se, pois elabora premissas para sua existência que o levam ao distanciamento de suas raízes.

No Primeiro discurso, expõe Luiz Roberto Salinas Fortes (1976. p. 49, grifo do autor), Rousseau apresenta a aparência na forma da polidez que "oculta alguma disformidade do indivíduo, que a ostenta, as guirlandas de flores - as artes, as letras e as ciências - escondem verdadeiras cadeias de ferro que prendem os cidadãos desta República". Numa sociedade em que reina a aparência, a polidez cria a dissimulação, porque o ser não se mostra, fica oculto na consciência, não tendo espaço para se manifestar numa 
sociedade que prima pelo que é alheio ao sujeito. A dissimulação ocorre, em primeira instância, no homem, consigo mesmo, para depois surgir na sociedade e na República das Letras. Segundo Rousseau, a causa para oposição entre ser e parecer ainda deve ser procurada, mas o efeito é certo, uma vez que culmina na depravação real dos homens.

$\mathrm{Na}$ passagem que se segue, evidencia-se como a aparência afeta o homem:

antes que a arte polisse nossas maneiras e ensinasse nossas paixões a falarem a linguagem apurada, nossos costumes eram rústicos, mais naturais, e a diferença dos procedimentos denunciava, à primeira vista, a dos caracteres. No fundo, a natureza humana não era melhor, mas os homens encontravam sua segurança na facilidade para se penetrarem reciprocamente, e essa vantagem, de cujo valor não temos mais noção, poupava-lhes muitos vícios. Atualmente, quando buscas mais sutis e um gosto mais fino reduziram a princípios a arte de agradar, reina entre nossos costumes uma uniformidade desprezível e enganosa, e parece que todos os espíritos se fundiram num mesmo molde: incessantemente a polidez impõe, o decoro ordena; incessantemente seguem-se os usos e nunca o próprio gênio (ROUSSEAU, 1978a, p. 335).

O filósofo identifica os homens agindo em sociedade de acordo com interesses, guiados por preconceitos, pelo erro, pela paixão, o que gera uma complexidade nas relações sociais e a artificialidade de suas necessidades. $\mathrm{O}$ que está em discussão não é um juízo de valor da natureza humana, mas sim a transformação ocasionada pelo convívio social, pois a aparência é ocasionada pelo princípio motor dos costumes e não da racionalidade. Há uma perda da individualidade, todos os que convivem se tornam uniformes, as forças humanas voltam-se contra os homens mesmos, porque a razão se divorcia do indivíduo.

Um possível desdobramento do pensamento rousseauniano é: ao mesmo tempo em que a sociedade é responsável pelas relações aparentes, é importante perceber que também o homem não pode escapar de sua responsabilidade por aquilo que existe. A esse paradoxo, Rousseau faz a dicotomia entre aparência e autenticidade, revelada entre a sociedade vigente na época e a solidão de tempos remotos, que caracteriza sua teoria da solidão, no sentido antropológico.

Na dicotomia existente entre aparência e autenticidade, uma questão a ser explorada é a consciência de si enquanto sujeito que não deve ser dominado por aquilo que lhe é externo. Ao oposto disso, é o indivíduo que não possui tal consciência e vive em função do exterior, achando que as coisas impostas pelo meio são essenciais para si. Ao discorrer sobre o aduzido, Starobinski (2011, p. 39, grifos do autor) expressa que:

a estima e a benevolência constituem um laço pelo qual os 


\begin{abstract}
homens se reúnem imediatamente: nada se interpõe entre as consciências, elas se oferecem espontaneamente numa evidência total. Em compensação, os laços ordenados pelo interesse pessoal perderam esse caráter imediato. A relação já não se estabelece diretamente de consciência para consciência: ela passa agora por coisas. A perversão que daí resulta provém não apenas do fato de que as coisas se interpõem entre as consciências, mas também do fato de que os homens, deixando de identificar seu interesse com sua existência pessoal, identificam-no doravante com os objetos interpostos que acreditam indispensáveis à sua felicidade. $\mathrm{O}$ eu do homem social não se reconhece mais em si mesmo, mas busca no exterior, entre as coisas; seus meios se tornam seu fim. O homem inteiro se torna coisa, ou escravo das coisas... A crítica de Rousseau denuncia essa alienação e propõe como tarefa o retorno ao imediato.
\end{abstract}

A alienação como fundamento da vida social faz o homem esquecer de si, e a solidão moral deixa de existir. Por solidão moral, deve-se entender aquela em que o indivíduo tem consciência de si e dos demais, não como coisas, mas como sujeitos autônomos que independem da estima pública para existirem ou formarem seu "eu". É a formação da subjetividade que está em jogo; as relações não são mais imediatas, o material, a estima e a benevolência fazem parte da ligação entre os homens. As relações passam, na vida alienada, a vigorar pelo princípio do mediato, as coisas fazem a mediação.

O homem social não existe por si, e, sim, em relação ao outro. Há opinião e julgamento dos demais. Com o mundo regido pelas relações estéreis, do ponto de vista da consciência de si, o indivíduo se desenha enquanto detentor de dignidade e reconhecimento, somente com o olhar alheio. $\mathrm{O}$ homem perde sua personalidade, a individualidade não faz mais parte dele, fica a cargo dos outros. Ante a inexistência de valores morais da sociedade alienada, onde cada indivíduo vive para a opinião alheia e, ao mesmo tempo, separado pelos limites impostos dos interesses particulares, o Primeiro discurso apresenta o seguinte: a solidão moral, como virtude, não é mais possível. Desta feita, como as virtudes morais não são mais o liame social, os interesses desestabilizam e distanciam os indivíduos, que veem sua subjetividade construída e mantida pelo jugo dos outros; o "eu" perde-se no olhar e nas diversas formas de se relacionar em sociedade.

Assim, a falta da solidão moral caracterizada em relações aparentes leva os homens a viverem numa comunidade que carece de valores universais. O interesse egoísta substitui o interesse pelo bem público, a alienação produz uma ruptura na existência humana, os homens não se reconhecem mais como verdadeiramente o são: livres. São guiados pela existência social, pela aparência, não reconhecendo mais as propriedades do gênero humano.

A implicação desse "viver fora de si" é que o tempo e as relações

A alienação como processo de desnaturação do indivíduo e sua nova existência social em Jean-Jacques Rousseau Juliana Fischer de Almeida 
sociais afastam o homem de si mesmo, rompendo com sua solidão. Criamse necessidades artificiais, paixões fictícias, comportamentos psíquicos distintos, que levam a uma falsa noção de tempo — que o tempo vivido desta forma é o mesmo de quando há consciência de si, porquanto o homem torna-se ignorante de si. O mundo torna-se para o homem um tanto quanto hostil, pois se sente constantemente ameaçado por aquilo que o rodeia, já que não se conhece o suficiente para distinguir o "eu" e os "outros". Na Passagem de Baczko (1974, p. 23), temos que:

nós somos incapazes de responder à questão de saber o que se passa na fronteira do mundo da alienação e da loucura; qual é o momento em que esta imagem se transforma em maldade, em delírio de perseguição, em imagem de um mundo experimentado como uma trama permanente na qual todos participam, [...] como uma conspiração universal anônima cujo significado permanece para ele obscuro.

A confusão proporcionada pelo mundo da alienação faz com que o "eu" se torne obscuro, ocasionando uma ruptura entre sua vocação e sua ação. Quando acontece a ruptura, o indivíduo cria necessidades artificiais e forja os laços da cadeia social, pois a artificialidade é criada no coração de um ser humano que não mais se conhece, que é alienado de si mesmo e capaz de produzir necessidades de acordo com a sociedade na qual está inserido. A interdependência dos homens provoca o agir do indivíduo não na sua pessoa; é um agir direcionado, não havendo uma harmonia das necessidades, pois cada um necessita desejar mais que o outro para se destacar socialmente, suscitando a ambição.

A ambição promotora da sociedade se estende ao Estado, criando-se um viés econômico da alienação. Segundo Rousseau (1978a, p. 344), "um homem só vale para o Estado pelo seu consumo", pois o consumo excessivo gera a aparência de superioridade de quem o possui, levando à negligência do que é realmente essencial para o bem-estar. $\mathrm{O}$ bem público, que deveria ser a busca incessante do Estado, acaba sendo deixado de lado, e os interesses particulares ganham primazia e destaque dentro da esfera política. Em decorrência disso, os valores são deturpados e os costumes se transformam, destacando-se o conflito de interesses como a norma régia do Estado, e não mais a harmonia e os bons costumes, conforme se observa:

de que precisamente se trata, pois, essa questão de luxo? Tratase de saber o que é mais importante para os impérios - seres brilhantes e momentâneos, ou virtuosos e duráveis. Digo brilhantes, mas qual o seu brilho? $\mathrm{O}$ gosto pelo fausto absolutamente não se associa, nas mesmas almas, como o da honestidade. Não, não é possível que espíritos degradados por um mundo de preocupações fúteis se elevem por uma vez a algo de grande e, se tivessem força, faltar-lhe-ia coragem (ROUSSEAU, 1978a, p. 345). 
Assim, com o tempo, a estrutura da lei e das instituições políticas e sociais passa a se transformar e a incorporar a vida autoalienante, dando existência a outro modo de vida social, descaracterizando a verdadeira existência. A alienação, por modificar a personalidade humana, acaba fazendo o homem querer se sentir em todos os lugares, pois como o ser e o parecer se tornam distintos, ele não se basta a si, não se conhece a ponto de desejar estar consigo mesmo. Dessa forma, necessita estar em todos os lugares e ser benquisto perante a sociedade.

$\mathrm{O}$ processo de alienação acontece, também, quando após o esquecimento de si, esquece-se a pátria, seus concidadãos, ocorrendo uma valorização que não pertence nem a si nem à pátria. Rousseau (1978a, p. 347), na passagem, faz a observação:

\begin{abstract}
já desde os primeiros anos, uma educação insensata torna nosso espírito e corrompe nosso julgamento. Vejo em todos os lugares estabelecimentos imensos onde a alto preço se educa a juventude para aprender todas as coisas, exceto seus deveres. Vossos filhos ignoram a própria língua, mas falarão outras que em lugar algum se usam; saberão compor versos que dificilmente compreenderão; sem saber distinguir o erro da verdade, possuirão a arte de torná-los ambos irreconhecíveis aos outros, graças a argumentos especiosos; mas não saberão o que são as palavras magnanimidade, equidade, temperança, humanidade e coragem; nunca lhes atingirá o ouvido a doce palavra pátria $[\ldots]$.
\end{abstract}

A educação corrobora para o processo alienante do indivíduo e, posteriormente, do cidadão. O filósofo crítica veementemente a maneira de se educar em sua época e escreve como resposta à alienação a má constituição das leis e dos Estados, o Emílio que deve se engajar na política, procurar entre todas as obras políticas as melhores virtudes e lutar por elas, amar seus concidadãos, formando o espírito.

Outro ponto relevante a ser apresentado na questão da alienação são as ciências e as artes, pois animam o sujeito pelo desejo de reputação, desprovidas de significação, exceto como exibicionismo pessoal. A busca pela verdade não é levada em consideração. No Primeiro discurso, objeto de análise, Rousseau faz uma leitura sobre a decadência moral e aponta que as ciências e as artes florescem em Estados cujo processo de alienação esteja instalado.

Com alienação, ocorre um desdobramento que é a desigualdade social, uma vez que, somente na distinção entre os homens, no âmbito moral, é que a desigualdade se aprofunda depois de já instalada pelo advento da desigualdade econômica, conforme $\mathrm{o}$ pensamento rousseauniano. A esse respeito, o filósofo faz o seguinte diagnóstico:

de onde nascem todos esses abusos senão da funesta 
desigualdade introduzida entre os homens pelo privilégio dos talentos e pelo aviltamento das virtudes? Aí está o efeito mais evidente de todos os nossos estudos, a mais perigosa de suas consequências. Não se pergunta mais a um homem se ele tem probidade, mas se tem talento; nem de um livro se é útil, mas se é bem escrito. As recompensas são prodigalizadas ao engenho e fica sem glórias a virtude. Há mil prêmios para os belos discursos, nenhum para as belas ações. Que me digam, no entanto, se é comparável com glória, conferida ao melhor dos discursos premiados nesta academia, ao mérito de ser instituído o prêmio (ROUSSEAU, 1978a, p. 348).

A degradação moral instaurada na alma do ser humano não valoriza as ações; somente os discursos desprovidos de utilidade, porque dão primazia à forma e não mais ao conteúdo. A República das Letras, na visão de Rousseau, é nefasta, as leis que a regem não são a de seres autônomos, promotores de seu destino, guiados pela voz da consciência e do silêncio, mas as da ambição e da estima alheia. Ao fim do Primeiro discurso, o filósofo faz o seguinte apelo:

não corramos atrás de uma reputação que nos escaparia e que, na situação atual das coisas, jamais nos devolveria o seu preço, ainda que tivéssemos todos os títulos para obtê-la. De que serve procurar nossa felicidade na opinião de outrem, se podemos encontrá-la em nós mesmos? Deixemos a outros o cuidado de instruir os povos sobre seus deveres e limitemo-nos a bem cumprir os nossos; não temos necessidade de saber mais (ROUSSEAU, 1978a, p. 352).

Rousseau faz um apelo para que os homens, como forma de bastarem a si mesmos, contemplem o silêncio, sendo este a condição sine qua non para se viver numa comunidade não pautada na reputação. Por fim, a questão de como a alienação contribui para a dissolução do "eu" pode ser respondida na medida em que o homem torna-se uma presença aparente do ser. O exterior o caracteriza e a oposição entre ser e aparecer torna-se o princípio norteador de sua análise social, pois a depravação real dos homens faz com que ocorra um distanciamento da sua existência. Numa sociedade em que reina a aparência, a polidez cria a dissimulação, porque o ser não se mostra, fica oculto na consciência, não tendo espaço para se manifestar numa sociedade que prima pelo que é alheio ao sujeito.

$O$ processo de alienação surte efeitos na solidão moral, na consciência de si e dos outros, não como coisas, mas como sujeitos autônomos que independem da estima pública para existir ou formar seu "eu". Os homens que não conseguem mais viver na solidão, pois carecem de valores universais, não se reconhecem mais como gênero humano. Os valores da aparência falam mais alto em seus corações, guiados não mais pela voz da natureza; os homens, portanto, encontram-se descentrados. Assim, a dissolução do "eu" acontece e o "eu" social se impõe, vivendo o 
homem fora de si.

Após analisar o processo de alienação e sua interferência para a dissolução do "eu" do ponto de vista das relações sociais, a reflexão situa-se em como acontece o processo de desnaturação do homem natural solitário que vivia no imediato e passa para o estado social com um novo tipo de existência. A questão a ser levantada do ponto de vista genético é a seguinte: em que sentido o processo de desnaturação esclarece o significado da solidão como virtude natural? O processo de desnaturação é importante para entender como Rousseau pensa o cidadão vivendo num Estado que lhe proporciona uma forma autêntica de ser e de se relacionar.

O processo de desnaturação do homem é entendido como aquele que forçou o ser humano a viver contra sua natureza, ocasionando um desequilíbrio entre o indivíduo e o meio natural. $\mathrm{O}$ homem passa a viver em conflito com o mundo que o cerca, ativando suas faculdades, cuja natureza proporcionava sua conservação, fazendo com que o selvagem, que bastava a si mesmo, entrasse num processo de socialização. Esse processo encontra na faculdade virtual do homem de se aperfeiçoar, de desenvolver suas necessidades, denominada perfectibilidade, uma de suas principais explicações. Tal faculdade faz o homem aprimorar a razão, acumular experiências e conhecimentos, individuais e sociais, para poder sobreviver. Starobinski (2011, p. 280, grifos do autor) faz a seguinte observação:

\begin{abstract}
o segundo Discurso atribuía à reflexão um papel ambíguo. Lembramo-nos, o poder da reflexão está ligado à perfectibilidade do homem. É simultaneamente pelo emprego das ferramentas e pelo desenvolvimento do juízo reflexivo que o homem emerge da animalidade. Tudo se põe então em movimento, mas esse movimento nos afasta da plenitude original: perverte-se, isto é, desvia-nos de nossa primeira natureza. O homem que reflete é um animal depravado, o que não implica essencialmente uma condenação moral: um animal depravado é um animal que abandona a via simples a que o conduzia o seu instinto. A reflexão nos fez perder a presença imediata do mundo natural; por isso, na teoria, o desenvolvimento da reflexão é exatamente contemporâneo da invenção dos primeiros instrumentos, por meio dos quais o homem doravante vai se opor à natureza. A civilização se constrói pela conjunção do pensamento reflexivo e da ação instrumental, e não é possível retroceder. Por mais desastrosa que tenha sido nossa ruptura com a clareza primitiva da experiência sensível, devemos considerá-la como irreversível e acomodar-nos ao nosso estado presente. Embora haja motivo para condenar os malefícios da reflexão, é preciso dizer também que ela fornece a prova da espiritualidade do homem.
\end{abstract}

O homem pode aprender como seu meio ambiente funciona e se adaptar como melhor lhe aprouver. Na medida em que o indivíduo vai adquirindo novos comportamentos, estes vão se consolidando em sua 
personalidade, aprimorando o intelectual humano. A reflexão tem um papel fundamental no aperfeiçoamento dessa faculdade, pois é parte fundante da civilização e do progresso humano.

A perfectibilidade leva o indivíduo ao "progresso", que se manifesta na história como força das coisas, pois o leva a uma inevitável evolução através das sucessivas mudanças. É um processo contraditório, pois ao mesmo tempo em que o homem se aprimora, ele se degenera. Não se realiza enquanto "eu" absoluto no meio social, mas a sucessão de mudanças é a alteração do estado das coisas, abrindo a possibilidade de extrapolá-las e adquirir novos conhecimentos acerca de si e do mundo que vive.

Sobre a questão da contradição da noção de perfectibilidade, Cassirer (1999, p. 76, grifos do autor) faz a seguinte observação:

[...] Rousseau conhece a expulsão do homem do paraíso da inocência; também ele vê na evolução do homem em direção a um ser racional uma espécie de "pecado original" que o exclui para sempre da felicidade segura e bem resguardada que desfrutou até então. Mas se Rousseau, nesse sentido, lamenta a "perfectibilidade" que distingue os homens de todos os outros seres vivos, ele também sabe que a salvação final só pode advir através dela. Pois apenas através dela [...] cresce no homem, afinal, a liberdade que o torna senhor do seu destino.

A perfectibilidade advém da inteligência humana, acompanhada de vícios e virtudes, pois ao passo em que ela emancipa o homem, que o aperfeiçoa e o distingue dos demais seres para poder sobreviver, por outro lado, ela o enreda nos males do convívio social, pautado na desigualdade e na escravidão. O filósofo sabia que não é possível viver num estado natural e que o ser humano necessita da razão, imprescindível à vida. Contudo, a crítica que se faz da perfectibilidade é com relação há um tipo de sociedade pautada plena não emancipação do sujeito capaz de exercer sua liberdade e escutar sua voz interior na tomada de decisões, mas sim numa comunidade onde reina a cobiça, o egoísmo, a escravidão e a desigualdade entre membros que deveriam ser iguais, pois são do mesmo gênero humano e dotados da mesma racionalidade.

O aprimoramento da razão também se deve às paixões, pois "só procuramos conhecer porque desejamos usufruir, e é impossível conceber por que aquele que não tem desejos ou temores dar-se-ia à pena de raciocinar" (ROUSSEAU, 1978b, p. 244). O sentimento é a fonte mais próxima das relações do homem com seu meio, que, além de produzir o conhecimento, conduz a existência. A essência do "eu" reside no querer, uma vez que é só pelo sentimento que se revela a profundidade do sentimento de si, é a fonte primitiva do "eu", lugar onde reside a consciência e a forma pela qual se age sem julgamentos ou interesses diversos da voz da consciência. 
Além do desenvolvimento racional, que estava latente no estado natural, o homem possui a capacidade de desenvolver certos sentimentos inatos, como o amor de si. Rousseau (1978b, p. 254) o conceitua:

[...] moderada em cada indivíduo, a ação do amor de si mesmo concorre para a conservação mútua de toda a espécie. Ela nos faz, sem reflexão, socorrer aqueles que vemos sofrer; ela, no estado de natureza, ocupa o lugar das leis, dos costumes e da virtude, com a vantagem de ninguém sentir-se tentado a desobedecer à sua doce voz; ela impedirá qualquer selvagem robusto de tirar a uma criança fraca ou a um velho enfermo a subsistência adquirida com dificuldade, desde que ele mesmo possa encontrar a sua em outra parte; ela, em lugar dessa máxima sublime da justiça racionada.

O amor de si orienta para seu próprio bem e é uma disposição naturalmente benigna, é uma manifestação individual da percepção consciente, regulando sua conduta, visando a controlar os impulsos nocivos à sua conservação. Num primeiro momento, como uma extensão do "eu" para os outros, contudo, continua trazendo consigo um temperamento único, que o individualiza em relação aos demais da sua espécie. É nessa individualidade que o homem natural possui, em potência, as características universais da natureza humana, colocando "o outro antes do eu, e uma concepção da humanidade que, antes dos homens, afirma a vida" (LÉVISTRAUSS, 1993, p. 45). O conhecimento sobre o "eu" não é desvinculado do meio no qual se vive, e é na relação com os outros que se constituem, portanto, natureza e sociedade. São partes integrantes do processo de formação de uma consciência sobre a existência.

O amor de si, no Livro IV do Emílio, apresenta-se como uma paixão natural, inata ao homem:

\begin{abstract}
a fonte de nossas paixões, a origem e o princípio de todas as outras, a única que nasce com o homem e nunca o abandona enquanto ele vive, é o amor de si; paixão primitiva, inata, anterior a todas as outras e de que todas as outras não passam, em certo sentido, de modificações. Neste sentido, todas, se quisermos, são naturais. [...]. O amor de si é sempre bom e sempre conforme a ordem. Estando cada qual encarregado de sua própria conservação, o primeiro e mais importante de seus cuidados é e deve ser zelar por ela continuamente; e como zelaríamos dessa maneira se não tivéssemos por ela o maior interesse? É preciso, portanto, que nos amemos para nos conservarmos, é preciso que nos amemos mais do que qualquer outra coisa, e, por uma consequência imediata do mesmo sentimento, amamos o que nos conserva (ROUSSEAU, 2004, p. 288).
\end{abstract}

O amor de si, exposto por Rousseau na referida obra, sustenta que a origem do autoconhecimento está vinculada ao sentimento e não à razão. $\mathrm{O}$ 
critério para se aferir a capacidade de sentirmos a voz da natureza, entrar em contato com o imediato e zelar por nós mesmos, dá-se por uma paixão primitiva. Contudo, esse amor que temos por nós, e que deve ser maior do que qualquer outro, não se vincula à ideia de um egoísmo ou de um não olhar para o outro, pois a noção aqui construída é a de que há uma conjugação entre o bem de si e o bem pelo outro - é um bem querer.

Todavia, no processo de desnaturação, o amor de si acaba se dissolvendo e se perdendo no coração dos homens, graças à transformação da existência, de pura para relativa, posto que, por mais que existam aspectos universais no "eu", a relativização amolda-se da seguinte maneira, de acordo com Backzo (1974, p. 97):

\begin{abstract}
Rousseau formula sua tese da "existência relativa, coletiva" do indivíduo com base na negação da sociedade existente, não aprovando tal situação. Esta tese não traduz uma atitude conformista; é uma expressão de uma oposição contra forças culturais que se impõem ao indivíduo que vive em sociedade. Se a personalidade é percebida como uma força exterior, como um meio que introduz a mudança, vive a vida com um intenso sentimento de ser particular em relação ao meio. "O homem natural" não se particulariza nas relações com seu meio, evidentemente, não reflete suas relações consigo mesmo; contudo, a existência que o indivíduo adquire na sociedade é uma "nova existência", não é simplesmente dado pelo meio social. Este meio pode ser conscientemente aceito ou refutado.
\end{abstract}

Com a formulação da existência relativa que leva a uma existência coletiva, o ser humano se desenvolve a partir da cultura, como efeito do processo de desnaturação. Este não se funda na liberdade, mas na desigualdade, colocando em risco a harmonia interna do indivíduo. A ampliação excessiva da cultura faz com que, de um lado, haja o aprimoramento da personalidade, com desenvolvimento da moral e do intelecto, e, de outro, ocorra a perda da autenticidade e da integralidade do homem como se encontrava no estado natural. Contudo, o natural não equivale a uma negação total da cultura, podendo aquele ser reproduzido no mundo deste, por meio da naturalização da cultura - uma aproximação do indivíduo com a natureza, combinando o desenvolvimento da personalidade e o envolvimento com o outro, com a mínima perda da autenticidade, proporcionando à natureza humana uma realização completa.

Além do problema da cultura, existe a noção de progresso, entendido como um sistema de referência negativa da consciência histórica. O progresso está associado ao percurso histórico, a continuidade da civilização como produto social pelo acúmulo de conhecimentos e de hábitos produtivos, instaurando novos modelos de vida e de realidade. O reconhecimento particular do progresso intelectual é um fato que decide a continuação e a orientação da história; contudo, não resolve o problema da 
história - nem, nela, o problema da desigualdade moral, fruto de um processo não homogêneo.

O processo histórico leva ao antagonismo social e à degradação moral entre os homens, pois a necessidade de conhecer e acumular conhecimento enriquece a consciência individual, mas reduz a consciência enquanto ser que basta a si mesmo. O progresso moral enriquece sua vida interior, entretanto, perde sua relação unívoca consigo mesmo; o indivíduo adquire a consciência de si e de sua liberdade, mas a perde ao mesmo tempo pela falta de ação, do experimentar sua liberdade e sua solidão.

No Segundo discurso, Rousseau relata dois tipos de desigualdade: a natural ou física e a moral ou política. A desigualdade física é estabelecida pela natureza e diz respeito à idade, à força do corpo e à saúde; por sua vez, a moral é autorizada pelos homens e consiste no privilégio de alguns em detrimento dos demais.

Com todas essas inúmeras transformações do homem nas relações humanas, a igualdade inerente ao homem, portanto, desaparece, instalandose a distinção entre pobres e ricos. Disso, resulta a servidão civil manifestada pelos ricos que subjugavam e dominavam os pobres. Com base nisso, a sociedade nascente encontrava-se num estado constante de guerras, sendo necessária a criação de um ente que defendesse as pessoas e seus respectivos bens. A passagem que segue corrobora com a assertiva:

\begin{abstract}
o rico, forçado pela necessidade, acabou concebendo o projeto que foi o mais excogitado que até então passou pelo espírito humano. Tal projeto constituiu em empregar em seu favor as próprias forças daqueles que o atacavam, fazer de seus adversários seus defensores, inspirar-lhes outras máximas e dar-lhes outras instituições que lhe fossem tão favoráveis quanto lhe era contrário ao direito natural. [...] Em uma palavra, em lugar de voltar nossas forças contra nós mesmos, reunamo-nos num poder supremo que nos governe segundo sábias leis, que protejam e defendam todos os membros da associação, expulsem os inimigos comuns e nos mantenham em concórdia eterna (ROUSSEAU, 1978b, p. 269).
\end{abstract}

Desse modo, como se pode observar, o responsável pela instituição do corpo político foi o rico, posto que era ele quem arcava com os prejuízos decorrentes das guerras. Sendo o mentor da ideia, previu vantagens para si, pois, além de preservar sua vida, legitimava com o direito seu patrimônio. Assim, pode-se compreender que, para Rousseau, a sociedade civil é anterior à figura do Estado, e que os homens, no afã de se manterem livres, aderiram a um pacto que perpetuava a desigualdade, o direito de propriedade de alguns, a miséria de uma maioria e a servidão. A seguir, o filósofo assevera:

todos correram ao encontro de seus grilhões, crendo assegurar sua liberdade, pois, com muita razão reconhecendo as 


\begin{abstract}
vantagens de um estabelecimento político, não contavam com a suficiente experiência para prever-lhes os perigos: os mais capazes de pressentir os abusos eram precisamente aqueles que contavam aproveitar-se deles, e até os prudentes compreenderam a necessidade de resolverem-se a sacrificar parte de sua liberdade para conservar a do outro, como um ferido manda cortar um braço para salvar o resto do corpo (ROUSSEAU, 1978b, p. 269).
\end{abstract}

O filósofo critica a sociedade e o Estado, uma vez que, quanto mais o homem se degenera, mais a sociedade civil se enfraquece - desigualdades - e mais o poder político se submete aos interesses de alguns - ricos -, gerando, destarte, um círculo vicioso. Assim, quando isso acontece, segundo Rousseau, todos igualam-se, uma vez que os súditos submetem-se a uma lei fundada na vontade do senhor, e esse só se sujeita às suas paixões; a noção de bem e de justiça desfalecem e, por fim, a lei do mais forte impera sobre as relações entre os homens, que retornam ao estado de natureza, só que diverso daquele do qual saíram (ROUSSEAU, 1978b, p. 280). Dito de outra forma, o ser humano perde-se numa busca cega e desmedida por algo que lhe é exterior, renunciando sua liberdade e sua vida em troca de uma ilusão, tornando-se um nada, um corrompido, que não sabe mais o que fazer e como agir ante os acontecimentos.

Em resposta à problemática apresentada sobre a "perfectibilidade" como sendo um processo que desencadeia o progresso e, ao mesmo tempo, acarreta a alienação social, pode-se afirmar que há uma aparente contradição. Ao mesmo tempo em que há o aprimoramento pelo advento de novos conhecimentos e experiências do mundo que o cerca, por outro lado, ele não se realiza enquanto "eu", estando cada vez mais afastado de si, deixando de escutar a voz do coração, abafando seu querer e seu sentir em detrimento da intersubjetiva advinda pelo progresso.

A perfectibilidade advém da razão humana e emancipa o homem, torna-se imprescindível à vida. Nesse sentido, cabe destacar que a noção de progresso deve ser entendida como uma forma de o homem sobreviver no meio em que vive, desenvolvendo-se moral e intelectualmente. A solução para isso é uma comunidade autêntica, descrita no Contrato social. A contradição apresentada é resolvida quando o filósofo teoriza sobre outro tipo de relação social; nele, escutar a consciência não equivale a uma negação total da cultura, podendo aquele ser reproduzido no mundo por meio da naturalização da cultura, que seria uma aproximação do indivíduo com a natureza. Tal intento somente é possível numa sociedade e num Estado em que os homens sejam livres e iguais, diferentemente do mundo fático. 


\section{Referências bibliográficas:}

BACZKO, B. Rousseau: solitude et communauté. Tradução de Claire Brendhel-Lamhout. Paris: Ecole Pratique de Hautes Etudes et Mouton \& Co, 1974.

CASSIRER, E. A questão Jean-Jacques Rousseau. Tradução de Erlon José Paschoal. São Paulo: Unesp, 1999.

FORTES, L. R. S. Rousseau: da teoria à prática. São Paulo: Ática, 1976

LÉVI-STRAUSS, C. Antropologia estrutural dois. Tradução de Sonia Wolosker. 4. ed. Rio de Janeiro: Tempo Brasileiro, 1993.

ROUSSEAU, J-J. Discurso sobre as ciências e as artes. Tradução de Lurdes Santos Machado. 2. ed. São Paulo: Abril Cultural, 1978a.

ROUSSEAU, J-J. Discurso sobre a origem e os fundamentos da desigualdade entre os homens. Tradução de Lurdes Santos Machado. 2. ed. São Paulo: Abril Cultural, 1978 b.

ROUSSEAU, J-J. Emílio ou da educação. Tradução de Roberto Leal Ferreira. São Paulo: Martins Fontes, 1995b.

STAROBINSKI, J. Jean-Jacques Rousseau: a transparência e o obstáculo. Tradução de Maria Lúcia Machado. São Paulo: Companhia das Letras, 2011.

TAYLOR, C. As fontes do Self: a construção da identidade moderna. Tradução de Ubirajara Sobral e Dinah de Abreu Azevedo. 2. ed. São Paulo: Loyola, 2005.

Autor(a) para correspondência: Juliana Fischer de Almeida, Pontifícia Universidade Católica do Paraná, R. Imac. Conceição, 1155 - Prado Velho, CEP 80215-901, Curitiba PR, Brasil.juliana_fisalm@yahoo.com.br 